\title{
A Study on the Safety Education of College Students under Background of the Internet Plus
}

\author{
Jiuhong Lv, Wei Lin \\ Gannan Medical Univercity, Ganzhou City, Jiangxi Province, 341000, \\ China
}

\begin{abstract}
Internet has become a new way to enhance the safety education of college students with its richness, flexibility, interestingness and openness. Especially, the popularization of the "Internet + " will greatly promote the safety education of college students. Based on the author's learning and work experience, this paper analyzed the challenges that the safety education of college students faces under the background of the "Internet + " and then discussed the application of typical Internet products in the safety education of college students. Finally, the article proposed countermeasures of the safety education in colleges under the background of the "Internet + ".

Keywords: "Internet+"; College students; Safety education; Challenges; Countermeasures
\end{abstract}

\section{Introduction}

In recent years, under the background of the popularization of the Internet and especially the appearance of Microblog, WeChat, QQ, APP and other Internet media which are closely related to people's lives, study and work, the "Internet +" is proposed. The reason why we connect the "Internet + " with education of university students is that the virtual space and physical space constructed by the Internet constitute the daily life of college students, and it has great influence on their life style, ideology and moral climate. In the safety education, although colleges and universities introduce Internet elements, it is that the Internet 
replaces the teaching materials and blackboard in traditional safety education[1]. Therefore, there is no major changes and innovations of the safety education content and form. This situation is just the "Internet+" state of the safety education of college students, and it is a far cry from the realization of the "Internet +".

\section{Challenges that the Safety Education of College Students Faces under the Background of the "Internet +"}

\subsection{The virtual nature of the Internet brings new forms of crime}

Students have strong learning ability and it is easy for them to grasp the network technology. However, because they have no experience of life and their world outlook, outlook on life and values are not yet fully mature, many of them will have the idea that the virtual network behavior does not require responsibility. In recent years, college students use network technology to conduct personal attacks on others, disseminate pornographic content and steal other users' account information illegally. At the same time, some students lack self-protection, and their prevention and right-protection awareness is weak. Therefore, it is easy for criminals to defraud them by using the virtual network.

\subsection{The diversity of the Internet affects the physical and mental health of college students}

The university stage is a period for students to widely accept information and knowledge, and form self-personality gradually. Information garbage in the network culture will greatly shock and affect their outlook of right and wrong. Colorful network culture can easily attract students to indulge in it and they are unable to extricate themselves. This seriously affect their normal life and study. Therefore, if student can not correctly treat the diversity of the network, it will inevitably hinder the formation of a sound personality of college students, which will lead to the decline of moral level of individuals or even groups[2].

\subsection{The openness of the Internet has weakened the authority of traditional education}

In Chinese traditional culture with more than 5,000 years, teachers are people who impart knowledge, instruct students and answer questions. Schools and teachers are the authority in the educational resources. However, with the popularization of network technology and the deepening of information acquisition and openness, the network as an advanced medium has gradually become an important way for educatees to obtain information. Its breadth and depth may even exceed the reach of educators. Undoubtedly, the authority and control ability of the traditional security education has been weakened. 


\section{The Application of Typical Internet Products in the Safety Education of College Students}

\subsection{Microblog}

Microblog is a platform for expressions with one sentence and it is a broadcasting social networking platform for users to share short real-time information with people they are following. The use of microblog in security education: (1) Establish real-name authentication microblog. Real-name authentication can increase the authority and trustworthiness of the subject in the information. (2) Make good use of micro-language. Colleges can prepare content suitable for student tastes with illustrations and pictures or short videos. (3) In the situation that the microblog has few fans and limited capacity to disseminate information, security education can use the official microblog of the college, student work microblog and student employment microblog to obtain fans. (4) Interact with receivers timely and insist on publishing content.

\subsection{WeChat}

WeChat is a smart and free terminal developed by Tencent to provide instant message services, and it is easy for people to share content. The specific ways to use WeChat in safety education: (1) Register WeChat public account. (2) Attract users' attention by developing services close to student life, such as "Lost and Found" and "Account Inquiry". Compared to microblog fans, most of WeChat users are students and faculty in the college. (3) Improve user stickiness through a variety of online and offline interaction. (4) Related research shows that the attention of information in the friend circle is higher than that of public account. Therefore, colleges can also establish a cascade linkage mechanism and spread important safety information in the friend circle.

\subsection{The instant message tool}

The instant message tool is a software to achieve online chat and exchanges with the use of instant message technology. By virtue of instant message tools, people can know if their friends and family are online and they can chat with them. The instant message takes less time to contact friends compared with the email and it is more convenient than dialing, which is undoubtedly the most convenient communication means for young people in the network age[3]. Tencent QQ is the instant message tool that people are most familiar with. A survey shows that college students rely more on QQ than WeChat and other new media currently. As a generation grew up with QQ, their emotions on QQ can not be understood by others. Therefore, the full understanding of students' use of QQ and the flexible application of QQ group or QQ space to carry out the dissemination of safety knowledge is an important breakthrough to achieve a qualitative change in the Internet + safety education. 


\section{Countermeasures of the Safety Education of College Students under the Background of the "Internet +"}

\subsection{To strengthen the top-level design and create a new pattern of joint management of safety education}

Safety education in colleges and universities involves law and order, fire fighting, transportation, safe production, food hygiene, mental health, national security and network security, so it is necessary to strengthen the top-level design from the school level and further integrate the educational resources and strength of the school to form a three-dimensional pattern with joint management of the college and school. Besides, colleges should insist on taking the characteristics of the Internet generation and growth risk as guidance and give full play to the security cadres, psychological counseling teachers, head teachers, instructors, professional teachers and other forces[4]. Moreover, colleges should establish and improve the safety education system that all people and college students are concerned about and all participate in to achieve comprehensive education. Colleges and universities that have the conditions can establish specialized research institutions of safety education to absorb and introduce social resources and talents to participate in the safety education in colleges and universities. They can also explore the establishment of a stable and professional security education research team, and set up the corresponding performance appraisal and incentive mechanism to encourage them to carry out teaching research and teaching innovation.

4.2 To develop a new safety education path for all people to participate in by virtue of the new media

Communication ways of new media are three-dimensional with illustrations audios and videos. It is widely pursued by the Internet generation. Colleges and universities can use micro films, animation, games to explore new methods of safety education for students to better stimulate their learning enthusiasm. Besides, colleges should combine the knowledge, ideology and politics in safety education work with intuition, interaction and entertainment of new media together, so that students can accept safety culture education, learn safety knowledge and improve safety skills in a relaxed atmosphere. This is bound to get twofold results with half the effort. In recent years, microblog, WeChat and other social networking platforms have become main channels for young people to communicate with others immediately. Colleges and universities can set up official microblog homepage and WeChat subscription account to regularly collect safety problems and campus hidden dangers that students concerned about. These platforms should use network languages that students are familiar with to respond timely and conduct publicity and warning education. It plays an important role in improving the full participation of all people in safety education. 


\subsection{To highlight the legal education and form a new situation of the safety education with the times}

At present, the relevant laws and regulations about the management of virtual society are continuously improved in China. Therefore, the relevant management provisions are not perfect. In this situation, many people do not know how to express their views or they have no courage to express themselves in colleges and universities. In view of this reality, it is recommended that colleges and universities can conduct work from three aspects: First, in the basic law courses, colleges should improve the proportion of the content of existing laws and regulations on the Internet and virtual society, so that students can understand that in the virtual society they also need to observe the basic ethics and they have legal responsibility on their words and deeds. Second, in the safety education campaigns and related courses, colleges ought to highlight the network security and telecommunication prevention to enhance students' awareness in the virtual society to maintain their own security, and encourage them to use the relevant legal weapons to protect personal interests. Third, colleges can carry out Internet law education activities jointly with the police, Internet information office and other relevant departments. By presenting and learning real cases, students can perceive the authenticity behind the virtual society to strengthen their awareness to observe the law.

\subsection{To insist on learning from each other and promote better integration of new and traditional education models}

The arrival of the Internet era does not mean that all safety education can be conducted online. Because of the lack of necessary supervision and coherence in learning time, online education does not have the power to replace traditional classroom education[5]. Therefore, colleges and universities should further consolidate the classroom education and practical exercises offline when opening the online safety education channels. The burgeoning online education channels should be an effective complement to the traditional classroom education. For example, students can launch exercises or discussions on security issues in the social network platforms, so as to make up for the limitations of time and space in the traditional classroom education. Only by grasping the relationship between the new safety education model and the traditional safety education model, can we maximize the effectiveness of the emerging safety education model by rationally running these models, strengthening mutual integration and complementing each other well.

\subsection{To make good use of the Internet thinking and update safety education methods and content timely}

The development of Internet brings an inevitable change of security education in colleges and universities. With the rapid development of Internet technology, the channels for college students to communication and gain information will update 
more quickly. Safety education educators in colleges and universities need to use the Internet thinking to adapt to the new normal of the Internet. The core of the Internet thinking is rapid response, and people-oriented and innovative spirit. In the future development of safety education in colleges and universities, teachers must adhere to people-oriented concept and constantly conduct in-depth study of students' thinking trends[6]. They should have the courage to develop innovative safety education methods and update the safety education content timely, so as to effectively improve the pertinence and effectiveness of safety education.

\section{Conclusion}

The safety education work of college students is the primary task of the ideological and political education, and the ideological and political education workers have a long way to go. In the current situation with the Internet as a new education medium, the Internet has become a new way to strengthen the safety education of college students with its richness, flexibility, interestingness and openness. The popularization of the Internet will play a huge role in promoting moral education of college students. Therefore, colleges and universities should vigorously strengthen the construction of the Internet, accelerate the work to promote the safety education into the network, and strive to open up a new situation in ideological and political education, so as to make due contribution to training qualified social citizens and high-quality talents.

\section{Acknowledgements}

The research work was supported by the scientific research topic in Gannan Medical Univercity, 2016, number: YB201631.

\section{References}

[1] Zheng Hengyi, Wang Wei and Liu Yu. An Exploration of Safety Education of College Students in the "Internet +" Era. Journal of Chongqing University (Social Science Edition), 04, pp.212-218, 2016.

[2] Yuan Zhikai, Zhang Yi. The International Internet Development and National Security Education of College Students. Journal of Ideological and Theoretical Education, 10, pp.38-41, 1999.

[3] Ma Silai. Thinking on the Network Security Education of College Students. Entrepreneur World, 10, pp.125-126, 2012.

[4] Huang Senhua. An Analysis of Safety Education of College Students in the "Internet +" Era. Modern Business Trade Industry, 31, pp.155-156, 2016.

[5] Jia Tingxiu. An Analysis of the Network Security Education. Economic and Social Development, 04, pp.140-143, 2003. 
[6] Nie Dujun, Xu Jian. An Exploration of Problems and Countermeasures of Network Security Education in Colleges and Universities. Education and Vocation, 30, pp.180-181, 2009. 